\title{
AGOTAMIENTO DEL DERECHO CONFERIDO POR LA MARCA DE LA UE
}

\section{EXHAUSTION OF THE RIGHTS CONFERRED BY TRADE MARKS IN THE EUROPEAN UNION}

\author{
Alicia Arroyo Aparicio \\ Profesora Titular de Derecho Mercantil \\ $U N E D$
}

Recibido: 16.06.2021 / Aceptado: 07.07.2021

DOI: https://doi.org/10.20318/cdt.2021.6251

\begin{abstract}
Resumen: El denominado agotamiento del derecho de marca constituye un límite al derecho de exclusiva sobre el signo, inherente a la naturaleza y función del derecho. Esto es, el agotamiento supone que el derecho exclusivo - de "exclusión comercial" - del titular de la marca acaba con la primera comercialización de los productos identificados con el signo realizada por él mismo o con su consentimiento. Llegado ese momento, la comercialización de los productos pasa a ser de libre comercio, de manera que el titular de la marca ya no puede utilizar su derecho para prohibir a los demás operadores que lleven a cabo una reventa bajo la misma, salvo -claro está- que existan motivos legítimos para que no sea así. Resulta de todo interés analizar el régimen vigente para las marcas de la Unión Europea y observar cómo esta materia es de total actualidad con ocasión de cuestiones como el re-etiquetado de medicamentos o las implicaciones anudadas al Brexit.

Palabras clave: Propiedad industrial, Derecho de Marcas, Reglamento de la Marca Europea, Artículo 15, agotamiento de los derechos conferidos por la marca, importaciones paralelas, empaquetado y re-etiquetado de productos marcados, Brexit y derechos de propiedad industrial.
\end{abstract}

Abstract: The so-called exhaustion of the trademark right constitutes a limit to the exclusive right over the sign, inherent to the nature and function of the right. In other words, exhaustion means that the exclusive right - of "commercial exclusion" - of the trademark owner ends with the first marketing of the goods identified with the sign carried out by him or with his consent. At that point, the "reselling" of the goods becomes free trade, so that the trademark owner can no longer use his right to prohibit other operators from reselling under the trademark, unless, of course, there are legitimate reasons for this not to be the case. It is of great interest to analyse the current regime for trademarks in the European Union and to observe how this matter is highly topical in the light of issues such as the relabelling of medicines or the implications of Brexit.

Keywords: intellectual property, trade-mark law, Regulation European Trade mark,article 15, exhaustion of the rights conferred by a trade mark, parallel imports, Repackaging of the product bearing the mark, New labelling- Brexit.

Sumario: I. Nociones previas: significado y generalidades; II. Requisitos: 1. Comercialización; 2. Consentimiento del titular de la marca: A) Titular de la marca; B) Consentimiento; C) En caso de licencia de marca; 3. Carga de la prueba; III. Importaciones paralelas, marcas de "origen común" y agotamiento; IV. Modificación del estado de los productos y otros motivos legítimos: A) Ideas previas; B) Re-envasado y re-etiquetado; C) Publicidad; D) Otros motivos legítimos. V. Algunos aspectos en relación con el Brexit. 


\section{Nociones previas: significado y generalidades}

1. El denominado agotamiento del derecho de marca constituye un límite al derecho de exclusiva sobre el signo, inherente a la naturaleza y función del derecho. Esto es, el agotamiento supone que el derecho exclusivo - de "exclusión comercial" - del titular de la marca acaba con la primera comercialización de los productos identificados con el signo realizada por él mismo o con su consentimiento. Llegado ese momento, la comercialización de los productos pasa a ser de libre comercio, de manera que el titular de la marca ya no puede utilizar su derecho para prohibir a los demás operadores que lleven a cabo una reventa bajo la misma, salvo -claro está- que existan motivos legítimos para que no sea así.

2. Puede entenderse, desde luego, que el agotamiento tiene un ámbito delimitado además por un territorio. De hecho, se ha distinguido tradicionalmente entre un agotamiento nacional, supranacional e internacional, según se esté en un determinado mercado. A nivel de la UE, el agotamiento se concreta al Espacio Económico Europeo, esto es, no se reconoce como internacional ${ }^{2}$, en tanto que no se permite que los Estados miembros puedan prever en los Derechos nacionales el agotamiento internacional. Y, como puede observarse, la referencia al Espacio Económico Europeo implica también que se comprende el territorio de la UE, así como el de Noruega, Islandia y Liechtenstein.

3. Este límite se expresó ${ }^{3}$ por vía jurisprudencial primero ${ }^{4}$, siendo después recogido para las marcas nacionales en el artículo 7, apartado 1, de la Directiva 89/104, posteriormente en el artículo 7, apartado 1, de la Directiva 2008/95 y, por último, en el artículo 15, apartado 1, de la Directiva 2015/24365.

4. La territorialidad de la marca es distinta si nos enfrentamos a marcas de ámbito europeo, habiéndose recogido en cuanto a los Reglamentos de marca comunitaria y europea, primero, en el artículo 13 del antiguo Reglamento y hoy en el artículo 15 Reglamento de $\operatorname{Marca}^{6}$ (RM), encontrando su fundamento en los 34 y 36 del $\mathrm{TFUE}^{7}$, cuyo tenor literal conviene tener presente:

"Agotamiento del derecho conferido por la marca de la Unión: 1. Una marca de la Unión no permitirá a su titular prohibir su uso para productos comercializados en el Espacio Económico Europeo bajo esa marca por el titular o con su consentimiento; 2. El apartado 1 no se aplicará cuando existan motivos legítimos que justifiquen que el titular se oponga a la comercialización ulterior de los productos, en especial cuando el estado de los productos se haya modificado o alterado tras su comercialización".

5. Puede afirmarse que el límite consistente en el agotamiento del derecho, que está incorporado a otros textos legales en relación también con otros derechos exclusivos de propiedad industrial, fue reconocido por la jurisprudencia del Tribunal de Justicia para precisamente resolver el conflicto entre la

${ }^{1}$ T. De las heras, "Marca comunitaria", Derecho de la Competencia y Propiedad Industrial en la Unión Europea, A. Bercovitz (Dir.), 2007, pp. 357-422, esp. p. 413.

${ }^{2}$ El tenor literal del artículo $15 \mathrm{RM}$ es claro, no permitiéndose que los Estados lo extiendan hasta el agotamiento internacional; confirmado respecto del texto de la Directiva (el artículo 7 de la Directiva) por: STJCE 16 julio 1998, C-355/96, Silhouette, ECLI:EU:C:1998:374 y STJCE 1 julio 1999, C-173/98, Sebago, ECLI:EU:C:1999:347. De fecha posterior puede verse también el auto de 28 octubre 2010, C-449/09, Canon Kabushiki Kaisha, ECLI:EU:C:2010:651, § 21 a 26.

${ }^{3}$ Sobre los antecedentes, A. CASADO CERviÑo, "La nueva doctrina del TJCE sobre el agotamiento del Derecho de marca: alcance, requisitos y límites", Comunicaciones en propiedad industrial y Derecho de la Competencia, $\mathrm{n}^{\circ}$ 46, 2007, pp. 25 y ss; esp. p. 27.

${ }^{4}$ La primera formulación se remonta a la STJCE de 31 octubre de 1974,C-16/74, Centrafarm yde Peijper, ECLI:EU:C:1974:115.

${ }^{5}$ Recuérdese que, en diciembre de 2015, el Parlamento Europeo y el Consejo adoptaron el paquete de reforma de la marca de la UE. El paquete contiene dos instrumentos legislativos: el Reglamento (UE)2017/1001 (el «RMUE)» y la Directiva (UE) 2015/2436 (la «Directiva»), que tienen por objeto aproximar las legislaciones de los Estados miembros en materia de marcas. Además de incluir nuevas disposiciones sobre cuestiones de derecho material y procesal.

${ }^{6}$ Como es sabido, el texto vigente en relación con la marca de la UE es el Reglamento (UE) 2017/1001 del Parlamento Europeo y del Consejo, de 14 de junio de 2017, sobre la marca de la Unión Europea (Texto pertinente a efectos del EEE).

${ }^{7}$ R. GARCía Pérez, El Derecho de Marcas en la UE en la jurisprudencia del Tribunal de Justicia, 2019, pg. 502 se refiere también a que el agotamiento se infiere del propio Tratado, trayendo a colación las Sentencias del TJ que citan expresamente los artículos del mismo. 
territorialidad del derecho de marca, que podría incluso suponer una compartimentación del mercado al titular, y el principio de libre circulación de mercancías en un mercado único. En efecto, sin la existencia del agotamiento, el titular de los derechos de marca podría oponer su derecho para impedir la importación de productos de un Estado a otro, lo que sería contrario a la libre circulación de mercancías ${ }^{8}$. Y, en el caso del agotamiento en el EEE, implica que el titular de una marca europea, nacional o internacional, protegida en un Estado miembro del EEE, no puede prohibir la ulterior comercialización de los productos bajo su marca en el EEE una vez que se han introducido en el mercado con su consentimiento dentro del EEE 9 .

6. Así es, el agotamiento europeo (se extiende como se ha dicho al EEE) implica que cuando los productos identificados con la marca han sido comercializados en cualquier Estado miembro de la UE o del Espacio Económico Europeo por el titular de la marca o con su consentimiento, ese producto puede ya circular libremente en todo el espacio europeo señalado, quedando el titular del derecho de marca sin la posibilidad de ejercitar tal derecho para impedirlo. Hasta tanto no se reconozca el agotamiento internacional, el titular de la marca podrá impedir la importación del producto marcado en el EEE, haciendo valer la territorialidad del derecho incluso aunque se trate de productos originales, es decir que hayan sido introducidos en el comercio fuera del EEE por el titular de la marca o con su consentimiento ${ }^{10}$.

7. En resumen, a la vista del régimen previsto en el artículo 15 del RMUE vigente, el límite al derecho exclusivo de marca que supone el agotamiento, tras la primera comercialización del producto original, con legitimidad de origen que proviene del comercio por el titular o con su consentimiento, implica que no se permite al titular prohibir a terceros el uso de la marca para productos ya comercializados con su consentimiento. Ahora bien, el derecho del titular no se agota si existen "motivos legítimos que justifiquen que el titular se oponga a la comercialización ulterior de los productos, en especial cuando el estado de los productos se haya modificado o alterado tras su comercialización". Para que tenga lugar el agotamiento del derecho de marca han de concurrir dos requisitos: por una parte, la comercialización en el EEE de los productos que llevan la marca, y, por otra, el consentimiento del titular de la marca a esta comercialización, o bien, que la haya realizado él mismo de forma directa. Cabe afirmar que, al tratarse de un límite al derecho exclusivo del titular de la marca, se observa una tendencia del Tribunal de Justicia a interpretar restrictivamente los requisitos que condicionan su aplicación ${ }^{11}$.

8. Se ha considerado a su vez que una razón económica que justificaba el agotamiento del derecho de marca tiene su fundamento en el intento de propiciar las importaciones paralelas ${ }^{12}$, que serían importaciones de productos originales que se producen dentro del Espacio Económico Europeo, realizadas por alguien ajeno al sistema de distribución del titular de la marca. Y la finalidad para favorecer esas importaciones paralelas era la de evitar la existencia de discriminación de precios haciendo valer los derechos de marcas.

9. Algunos aspectos generales pueden adelantarse también respecto del régimen jurídico diseñado en el RMUE. En primer lugar, ha de considerarse, en relación con el artículo 15 que, en tanto que se cumplan los requisitos del primer párrafo y no concurriendo lo previsto en el segundo párrafo, las consecuencias jurídicas del agotamiento tendrán lugar, puesto que esas consecuencias no dependen de la aprobación del titular de la marca para revender los productos marcados en el EEE ${ }^{13}$. Así mismo, el agotamiento se concreta a los productos marcados, esto es, los derechos conferidos por la marca sólo se agotan respecto de los ejemplares del producto que hayan sido objeto de una primera comercialización

\footnotetext{
${ }^{8}$ A. BeKEma "Artículo 15. Exhaustion of the rights conferred by an EU trade mark", European Union Trade Mark Regulation, (EU) 2017/1001, ed. G. N. Hasselblatt, $2^{\mathrm{a}}$ ed., 2018, pp. 444 a 459, esp. pg. 445.

${ }^{9}$ T. DE LAS HERAS, "Marca comunitaria", cit., pg. 414.

${ }^{10}$ T. De las heras, "Marca comunitaria", cit., pg. 414.

${ }^{11}$ Conclusiones AG Paolo Mengozzi, 12 septiembre 2017, C291/16, Schweppes, ECLI:EU:C:2017:666, § 29.

${ }^{12}$ M. Lobato, Comentario a la Ley 17/2001, de marcas, $2^{\text {a }}$ ed., 2007, p. 594.

${ }^{13}$ STJCE 30 noviembre 2004, C-16/03, PEAK HOLDING, ECLI:EU:C:2004:759, § 52.
} 
(producto original $\mathrm{l}^{14}$ ), pues “con respecto a otros ejemplares del mismo producto que no hayan sido objeto de tal primera comercialización en el EEE, el titular siempre puede prohibir la utilización de la marca en méritos del derecho exclusivo que le confiere la Directiva 89/104 (véase, en este sentido, la sentencia de 1 de julio de 1999, C-173/98, Sebago y Maison Dubois, ECLI:EU:C:1999:347, § 19 y 20)"15. Conviene subrayar en relación con lo señalado ahora que el alcance del término "comercialización" también ha de ser delimitado conforme a la jurisprudencia del TJUE, como requisito del agotamiento y que se analiza a continuación.

10. En suma, el agotamiento del derecho ha sido tradicionalmente un asunto de peso al abordar el derecho de marca de la UE, que recobró toda su fuerza desde el paquete europeo con los instrumentos legislativos nuevos (Directiva 2015/2436 y el RMUE), seguida de algunos pronunciamientos que vendrán como respuesta a cuestiones prejudiciales de interés ${ }^{16} \mathrm{y}$ con la incidencia del Brexit. Por estas razones, se hace aquí un repaso de los requisitos, la relevancia de las importaciones paralelas, los motivos legítimos requeridos para que no tenga lugar el agotamiento, así como el apunte de algunos retos que el Brexit plantea.

\section{Requisitos}

\section{Comercialización}

11. Se alude a la comercialización de los productos marcados como requisito objetivo del agotamiento del derecho. Para considerar que exista comercialización se exige que se incorpore el signo al producto y que éste rebase el ámbito externo de la empresa, sin que sea preciso que exista una enajenación, aunque será lo habitual ${ }^{17}$. El TJCE abordó ya este término en el año $2004^{18}$, aunque referido a la DM, y concluyó que el artículo 7 de la DM debía interpretarse como que "no podía considerarse que los productos que llevan una marca comercial han sido comercializados en el EEE donde el titular de la marca los ha importado al Área Económica Europea con el fin de venderlos allí o donde los haya registrado. Los ofreció a los consumidores para su venta en el EEE, en sus propias tiendas o en las de una tienda asociada, sin venderlos realmente". En esta Sentencia se analizaba si la exigencia de una comercialización efectiva y no solo de la voluntad de comercializar bastaban a los efectos de ver cumplido el requisito objetivo del agotamiento. El Tribunal concluyó que únicamente una venta que permite a su titular hacer efectivo el valor económico de su marca agota los derechos exclusivos otorgados por el derecho de marcas, lo que no tendría lugar cuando los productos no se venden finalmente ${ }^{19}$ (realizando en cierto modo una delimitación negativa ${ }^{20}$ ). En esa ocasión, el TJCE indicó también que la inclusión en el contrato de compraventa de una prohibición de reventa afecta únicamente a las relaciones entre las partes, de manera que no excluye que exista comercialización dentro del mercado interior. En definitiva, si tiene lugar la reventa en el EEE (los productos con la marca se venden efectivamente y el titular puede «hacer efectivo el valor económico de su marca» y los terceros adquirir «el derecho a disponer

\footnotetext{
${ }^{14}$ M. Lobato, Comentario a la Ley 17/2001, de marcas, p. 594.

${ }^{15}$ STJUE 3 junio 2010, C127/09, Coty Prestige, ECLI:EU:C:2010:313, § 31.

${ }^{16}$ Petición de decisión prejudicial planteada por el Sø- og Handelsretten (Dinamarca) el 29 mayo 2020 — Merck Sharp \& Dohme BV, Merck Sharp \& Dohme Corp., MSD DANMARK ApS, MSD Sharp \& Dohme GmbH, Novartis AG, FERRING LÆGEMIDLER A/S y H. Lundbeck A/S / Abacus Medicine A/S, Paranova Danmark A/S y 2CARE4 ApS, (C-224/20). De entre las cuestiones prejudiciales se destaca la que versa sobre el artículo 15, apartado 2, del Reglamento 2017/1001 para determinar si el titular de una marca puede oponerse a la comercialización ulterior de un medicamento que un importador paralelo haya re-envasado en un nuevo envase externo en el que se haya vuelto a colocar la marca.

${ }^{17}$ T. De las heras, El agotamiento del derecho de marca, Montecorvo, 1994, p. 238; P. Martín aresti, Comentarios a la Ley de Marcas, (A. Bercovitz, Dir.), 2 ed., 2008, sub artículo 36, p. 581.

${ }^{18}$ STJCE 30 noviembre 2004, C-16/03, PEAK HOLDING AB c. AXOLIN-ELINOR AB, ECLI:EU:C:2004:759.

${ }^{19}$ A. CASAdo CERviÑo, "La nueva doctrina del TJCE sobre el agotamiento del derecho de marca: alcance, requisitos y límites", cit., p. 33.

${ }^{20}$ BeKema, op. cit., p. 447.
} 
de los productos designados con la marca ${ }^{21}$ ), hay comercialización y existe el agotamiento del derecho exclusivo del titular de la marca.

12. El titular de la marca no puede tampoco impedir que los terceros, que tienen los productos distinguidos a su disposición, puedan anunciar al público su ulterior comercialización ${ }^{22}$ o anunciar la prestación de un servicio respecto de los $\operatorname{mismos}^{23}$, siendo esto último claro en tanto que el derecho se haya agotado. Estos usos pueden llevarse a cabo si no inducen a confusión respecto del origen o menoscaban la reputación del signo ${ }^{24}$.

13. A propósito del concepto de "productos comercializados", se ha considerado, por otra parte, que no existe ni comercialización ni consentimiento a efectos del agotamiento en relación con los denominados "probadores" de perfumes. En concreto, así se consideró en el caso de "probadores", puestos por el titular de una marca a disposición de un depositario perteneciente a una red de distribución selectiva, en la medida en que "se produce sin transmisión de propiedad y con prohibición de venta, en las que el titular de la marca puede en todo momento retirar dichos productos y en las que la presentación de éstos se distingue claramente de la de los frascos de perfume habitualmente puestos a disposición de esos intermediarios por el titular de la marca"; en definitiva, "el hecho de que tales probadores sean frascos de perfume que contienen las menciones «prueba» y «prohibida su venta», se oponen a que se reconozca tácitamente el consentimiento del titular de la marca a su comercialización, a falta de todo elemento probatorio en sentido contrario, cuya apreciación corresponde al órgano jurisdiccional remitente" 25 . Se reitera después por el TJUE nuevamente en sentido similar, esto es, la no consideración de comercialización a efectos de agotamiento, cuando se entrega a los distribuidores autorizados productos designados por la marca, destinados a la prueba o de los que puedan tomarse pequeñas cantidades para distribuir a los consumidores como muestra gratuita, respecto de los que en conclusión se entiende que "no constituye, a falta de elementos de prueba en sentido contrario, una comercialización en el sentido de la Directiva 89/104 o del Reglamento n 40/94"26.

14. En relación con el requisito de comercialización, aunque no específicamente -o no solo- a efectos de agotamiento, cabe mencionar los denominados supuestos de tránsito de mercancías marcadas. Las mercancías en ese caso no se consideran comercializadas, aunque el titular de una marca tampoco puede oponerse a la mera entrada en la Comunidad, "bajo el régimen aduanero de tránsito externo o de depósito aduanero, de productos originales de la marca que no han sido anteriormente comercializados

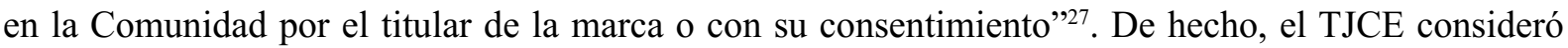
respecto de la DM 89/104 y el artículo 9.2.b del RM 40/94 que "los conceptos de «ofrecimiento» y de «comercialización» de productos pueden incluir, respectivamente, el ofrecimiento y la venta de productos originales de una marca que posean el estatuto aduanero de mercancías no comunitarias cuando el ofrecimiento se efectúa y/o la venta se realiza mientras que dichas mercancías se encuentran bajo el régimen de tránsito externo o de depósito aduanero". Con la consecuencia de considerar que el "titular de la marca puede oponerse al ofrecimiento o a la venta de dichas mercancías cuando impliquen necesariamente la comercialización de éstas en la Comunidad”28.

\footnotetext{
${ }^{21}$ Conclusiones AG Paolo Mengozzi, 12 septiembre 2017, C291/16, Schweppes, ECLI:EU:C:2017:666, § 30, hacienda resumen de la STJCE recaída en el asunto PEAK HOLDING.

${ }^{22}$ STJCE 23 febrero 1999, C-63/97, BMW - DEENIK, ECLI:EU:C:1999:82, § 48, citando a su vez a la STJCE de 4 noviembre 1997, C-337/95, Parfums Christian Dior, ECLI:EU:C:1997:517.

${ }^{23}$ P. Martín AResti, Comentario, sub artículo 36, cit., p., 581.

${ }^{24}$ STJCE 4 noviembre 1997, C337/95, Parfums Christian Dior, ECLI:EU:C:1997:517, § 59.

${ }^{25}$ STJUE 4 junio 2010, C-127/09, Coty Prestige, ECLI:EU:C:2010:313, referida al artículo 13 del RM año 1994.

${ }^{26}$ STJUE 12 julio 2011, C-324/09, L'Oréal -E-Bay, ECLI:EU:C:2011:474, § 73. V.A. GARCÍA VIDAL, "La comercialización de productos de marca ajena en mercados electrónicos (Sentencia del TJUE, de 12 de julio, en el caso L'Oréal-eBay), G-AP, julio 2011, pp. 1 y ss.

${ }^{27}$ STJCE 18 octubre 2005, C-405/03, Class International B.V. - SmithKline Beecham Plc, ECLI:EU:C:2005:616, § 50.

${ }^{28}$ STJCE 18 octubre 2005, C-405/03, Class International B.V. - SmithKline Beecham Plc, ECLI:EU:C:2005:616, en el fallo.
} 
15. El denominado tránsito externo de mercancías no comunitarias no es propiamente una actividad ajena al mercado interior; sería en realidad un supuesto de ficción legal al considerarse que no han entrado en el territorio europeo. Las mercancías incluidas en dicho régimen no están sujetas a los derechos de importación ni a las demás medidas de política comercial, como si no hubieran entrado en territorio comunitario ${ }^{29}$. El mero tránsito no implica comercialización y por consiguiente no hay posibilidad de que atente contra el objeto específico del derecho de marca ${ }^{30}$. Ahora bien, cuando los productos en cuestión sean objeto de un acto de un tercero efectuado mientras los productos estén incluidos en el régimen de tránsito externo y que necesariamente implique su comercialización en el Estado miembro de tránsito, entonces el titular del derecho de marca sí que podría oponer su derecho ${ }^{31}$.

16. Otro supuesto sería el de mercancías designadas con marca que se incluyen posteriormente en el régimen de impuestos especiales; en este caso se consideró que el titular de una marca registrada en uno o varios Estados miembros "puede oponerse a un tercero que, sin el consentimiento de dicho titular, ha introducido en el EEE y despachado a libre práctica mercancías designadas con esa marca". De otro modo se estaría limitando al titular la posibilidad de controlar la primera comercialización de productos designados con esa marca en el EEE: la importación de productos sin el consentimiento del titular de la correspondiente marca y su almacenamiento en un depósito fiscal hasta su puesta a consumo en la Unión impiden que el titular de esa marca pueda controlar la manera en que tiene lugar la primera comercialización en el EEE de los productos designados con tal marca ${ }^{32}$. Esos actos menoscabarían la función de la marca consistente en identificar a la empresa de la que proceden los productos y bajo cuyo control se efectúa la primera comercialización.

17. Todavía cabe señalar que se ha apreciado como infracción de marca la supresión de los signos idénticos a la marca y la colocación de nuevos signos en los productos en régimen de depósito aduanero con el fin de efectuar su primera comercialización en el $\mathrm{EEE}^{33}$.

\section{Consentimiento del titular de la marca}

\section{A) Titular de la marca}

18. La referencia en las normas antecedentes a la aquí analizada y en la jurisprudencia es al "titular" ${ }^{34}$. Por titular de la marca se considera el que la ha registrado, así como también, en relación con el consentimiento del "titular", se ha considerado suficiente a los efectos del agotamiento el prestado por una compañía perteneciente al mismo grupo - "económicamente vinculados"- del titular de la marca ${ }^{35}$. Y, más aún, cuando no exista vínculo económico, si se entiende que el titular de la marca renuncia a sus derechos exclusivos ${ }^{36}$, se entendería también cumplido el requisito del consentimiento que se explica con más detalle a continuación.

\footnotetext{
${ }^{29}$ STJCE 6 abril 2000, C-383/98, The Polo/Lauren Company LP v. Dwidua, ECLI:EU:C:2000:193, § 34.

${ }^{30}$ STJCE 23 octubre 2003, C-115/02, Rioglass, ECLI:EU:C:2003:587, § 27.

${ }^{31}$ STJCE 9 noviembre 2006, C281/05, Montex Holdings Ltd., ECLI:EU:C:2006:709, § 23.

${ }^{32}$ STJUE 16 julio 2015, C379/14, TOP Logistics BV, ECLI:EU:C:2015:497, § 48 у 49.

${ }^{33}$ STJCE 25 julio 2018, C129/17, Mitsubishi - Duma, ECLI:EU:C:2018:594.

${ }_{34}$ "Tanto el consentimiento del titular como la comercialización por éste en el EEE, que equivalen a una renuncia al derecho exclusivo, constituyen elementos que determinan la extinción de este derecho (véase, por lo que respecta al consentimiento, la sentencia Zino Davidoff y Levi Strauss, antes citada, apartado 41)": cit. en STJCE de 8 abril 2003, C-244-00, Van Doren, ECLI:EU:C:2003:204, § 34.

${ }^{35}$ STJ 22-VI-1994, C-9/93, as. IHT Internazionale Heiztechnik v. Ideal-Standard, ap. 34, textualmente: "o cuando, incluso siendo personas distintas están económicamente vinculados".

${ }^{36}$ STJUE 15 octubre 2009, MAKRO, C-324/08, ECLI:EU:C:2009:633, § 25, textualmente: "la voluntad de renunciar al derecho exclusivo previsto en el artículo 5 de la Directiva 89/104 puede resultar de un consentimiento tácito del citado titular".
} 


\section{B) Consentimiento}

19. El titular de una marca puede impedir que los productos originales que llevan esa marca se pongan en el mercado en el EEE por primera vez sin su consentimiento ${ }^{37}$ (en interpretación del artículo 5 de la Primera Directiva 89/104/CEE del Consejo, de 21 de diciembre de 1988, que aproxima las leyes de los Estados miembros en materia de marcas; art. 9.3 RMUE). En efecto, tal como ha reconocido el TJUE en repetidas ocasiones, el objeto específico del derecho de marca consiste en conferir al titular el derecho a utilizar la marca "para la primera comercialización de un producto", buscando la protección contra los competidores que "pretendan abusar de la posición y de la reputación de la marca vendiendo productos designados indebidamente con ella"38. En este sentido, confróntese también el Preámbulo del RMUE: "no puede prohibir su uso a un tercero, en el caso de productos que hayan sido comercializados en el Espacio Económico Europeo con dicha marca por él mismo o con su consentimiento, a no ser que existan motivos legítimos que justifiquen que el titular se oponga a la comercialización ulterior de los productos".

20. Por tanto, el consentimiento a estos efectos sería el requisito subjetivo que ha de cumplirse, constituye el elemento determinante, y debe manifestarse de una manera que refleje con certeza la voluntad del titular de renunciar a su derecho ${ }^{39}$. Puede entenderse prestado cuando la comercialización de los productos la efectúa un operador económicamente vinculado al titular de la marca, como pueda ser, por ejemplo, un licenciatario ${ }^{40}$.

21. Como es sabido, por otra parte, se superó en esta materia la denominada doctrina del "origen común" -de especial relevancia en el caso de marcas nacionales independientes e importaciones paralelas- en el sentido de plantearse si la cesión de una marca agotaba los derechos sobre marcas paralelas del cedente ${ }^{41}$. Así, dejada sin efecto dicha doctrina, en caso de que haya una cesión de marca, habrá de analizarse conforme a los criterios generales, esto es, comercialización y consentimiento por el titular, habiéndose considerado por otra parte que el consentimiento contractual referido a la transmisión no puede equipararse al consentimiento a efectos de agotamiento ${ }^{42}$ (v. infra IV, más extensamente).

22. Con independencia de lo referido en el párrafo anterior, el consentimiento no es preciso que sea expreso, puede resultar un consentimiento tácito ${ }^{43}$. Así, se considera que existe consentimiento en el caso de que sea una empresa del mismo grupo que aquélla que pretende hacer valer sus derechos de marca para impedir la comercialización, siempre que se esté ante una relación actual. Esto es, como se ha indicado antes, la comercialización por un tercero se entiende llevada a cabo con el consentimiento del titular cuando el tercero es una persona vinculada al titular mediante una relación de dependencia económica o jurídica $^{44}$. Y el fundamento en este caso reside en que al existir esa vinculación o relación cabe considerar que los productos han sido fabricados bajo el control de una única empresa a la que puede hacerse responsable de su calidad, considerándose que se puede asegurar el cumplimiento de la función de marca ${ }^{45}$.

23. Si el consentimiento es implícito los elementos que debieran tomarse en cuenta para determinar su existencia deben revelar con certeza la renuncia del titular de la marca para oponer su derecho

\footnotetext{
${ }^{37}$ Orden de 28 de octubre de 2010, C-449/09, Canon / IPN.

${ }^{38}$ STJUE 20 diciembre 2017, C291/16, Schweppes, ECLI:EU:C:2017:990, § 37.

${ }^{39}$ STJCE 30 noviembre 2004, C-16/03, PEAK HOLDING, ECLI:EU:C:2004:759, § 52 у 53.

${ }^{40}$ Conclusiones AG Paolo Mengozzi, 12 septiembre 2017, C291/16, Schweppes, ECLI:EU:C:2017:666, § 33, con cita de las sentencias STJCE de 22 junio 1994, C9/93, IHT Internationale Heiztechnik y Danzinger, ECLI:EU:C:1994:261, § 34; SSTJUE de 23 abril 2009, C-59/08, Copad, ECLI:EU:C:2009:260, § 43, y de 15 octubre 2009, C-324/08, MAKRO, ECLI:EU:C:2009:633, $\S 24$.

${ }^{41}$ Conocido AS. HAG II, STJCE 17 octubre 1990, C-10/89, ECLI:EU:C:1990:359.

${ }^{42}$ P. Martín aresti, P., Comentarios, sub art. 36, cit., p. 582.

${ }^{43}$ STJCE 20 noviembre 2001, C414/99, Zino Davidoff y Levi Strauss, ECLI:EU:C:2001:617.

${ }^{44}$ STJCE 22 junio 1994, C-9/93, IHT Internazionale Heiztechnik v. Ideal-Standard, ECLI:EU:C:1994:261, § 34

${ }^{45}$ P. Martín AResti, Comentarios, sub art. 36, cit., p. 582, con cita de la famosa STJCE 17 octubre 1990, C-10/89, HAG II, ECLI:EU:C:1990:359 y STJCE IHT Internazionale Heiztechnik, cit., § 34.
} 
exclusivo. Así, no sería suficiente que el titular de la marca no prohibiera a sus distribuidores fuera de la UE y del EEE que vendieran en dicho territorio, ni tampoco es relevante la ausencia de un efectivo control por parte de aquél sobre la comercialización posterior de los productos ${ }^{46}$.

24. En resumen, el consentimiento ${ }^{47}$ no debe deducirse: (i) ni del simple silencio; (ii) ni de la circunstancia de que no se hayan establecido reservas contractuales en la transmisión de la propiedad de los productos; (iii) ni de que el titular de la marca no haya comunicado una oposición a la comercialización; (iv) ni de que no se haya indicado en los productos la prohibición de comercialización en el EEE.

\section{C) En caso de licencia de marca}

25. El otorgamiento de una licencia es muy frecuente en relación con las marcas. En caso de existencia de una licencia será necesario considerar las limitaciones que el licenciante haya fijado en el contrato. En el RMUE se recoge -al igual que en los anteriores textos- (art. 25.2) que el titular de la marca de la Unión podrá alegar los derechos conferidos por la marca frente al licenciatario que infrinja alguna de las cláusulas del contrato de licencia relativas: a) a su duración; b) a la forma amparada por el registro bajo la que puede utilizarse la marca; c) a la naturaleza de los productos o de los servicios para los cuales la licencia se conceda; d) al territorio en el cual pueda fijarse la marca, o e) a la calidad de los productos fabricados o de los servicios prestados por el licenciatario. Al referirse la norma a las limitaciones recogidas en el clausulado del contrato, se trataría de cláusulas que quedan sometidas, por una parte, al Derecho Antitrust y que, por otra, delinean el consentimiento prestado por el titular para que el licenciatario haga uso del signo, con la relevancia de suponer, en caso de infracción de esos límites, una infracción a su vez del derecho de marca ${ }^{48}$, aunque con los relevantes matices que se apunta a continuación.

26. En primer lugar, resulta fundamental tener en consideración el matiz pertinente en referencia a las limitaciones territoriales. Puesto que, en este caso, si el licenciatario introduce los productos marcados en un territorio distinto al que estaba autorizado en virtud de la licencia ("en el cual pueda fijarse la marca"), cabe considerar que el derecho de marca estaría agotado y de esa situación se derivaría una infracción del contrato de licencia ${ }^{49}$, pero no una violación de marca que permitiera al titular invocar su derecho.

27. Otros matices pueden ser considerados en esta materia, aunque no siempre tengan una directa conexión con el agotamiento, pudiendo ser considerados y valorados caso por caso. Así, por ejemplo, en relación con la calidad de los productos fabricados, también se ha planteado que ha de matizarse, en tanto que la posibilidad de control que tiene el licenciante sobre el licenciatario impide al primero alegar violación de su marca cuando el licenciatario no respeta las normas de calidad. En ese sentido se expresó el TJCE, textualmente: "es importante subrayar por último que el elemento determinante es la posibilidad de un control sobre la calidad de los productos y no el ejercicio efectivo de dicho control.

\footnotetext{
${ }^{46}$ A. Bercovitz, Introducción a las marcas y otros signos distintivos en el tráfico económico, p. 148.

${ }^{47}$ STJCE 20 noviembre 2001, C414/99, Zino Davidoff y Levi Strauss, ECLI:EU:C:2001:617 se expresa en estos términos: El consentimiento implícito no puede inferirse: del hecho de que el titular de la marca no ha comunicado a todos los compradores posteriores de los productos comercializados fuera del Espacio Económico Europeo su oposición a la comercialización dentro del Espacio Económico Europeo; que los productos no advierten sobre la prohibición de su comercialización en el Espacio Económico Europeo; el hecho de que el titular de la marca haya transferido la propiedad de los productos que llevan la marca sin imponer ninguna reserva contractual y que, de acuerdo con la ley que rige el contrato, el derecho de propiedad transferido incluye, en ausencia de tales reservas, un derecho ilimitado de reventa o, como mínimo, un derecho a comercializar los productos posteriormente dentro del Espacio Económico Europeo. El alcance de esta Sentencia fue reconocido en la STJUE 15 octubre 2009, C-324/08, MAKRO, ECLI:EU:C:2009:633, § 26 y siguientes, de manera que el consentimiento puede desprenderse de modo tácito de "circunstancias anteriores, concomitantes o posteriores a esta comercialización que, apreciadas por el juez nacional, reflejen de manera cierta la renuncia del titular a su derecho" (AG Paolo Mengozzi, 12 septiembre 2017, C291/16, Schweppes, ECLI:EU:C:2017:666, § 33).

${ }^{48}$ P. Martín AResti, Comentarios, sub art. 36, p. 583.

${ }^{49}$ P. Martín AResti, Comentarios, sub art. 36, cit., p. 584.
} 
De este modo, una ley nacional que ofreciera al cedente la posibilidad de alegar la mala calidad de los productos del licenciatario para oponerse a su importación debería ser inaplicada por ser contraria a los artículos 30 y 36 . Si el cedente tolera la fabricación de productos de mala calidad a pesar de tener los medios contractuales para impedirlo, tiene que asumir la responsabilidad que de ello resulte"

28. Así mismo, aunque relacionado con el "aura de prestigio de la marca" y no con el agotamiento en sí aislado, el TJUE se refirió a que el titular de una marca puede invocar los derechos conferidos por esa marca contra un titular de la licencia que contravenga una disposición en un acuerdo de licencia que prohíbe, por razones de prestigio de la marca, las ventas a tiendas de descuento de bienes como los de la cuestión analizada en el procedimiento principal, siempre que se haya demostrado que esa infracción, en razón de la situación prevaleciente en el caso principal, daña el atractivo y la imagen de prestigio que otorga a esos productos un aura de lujo ${ }^{51}$. Pero resulta claro que en esta materia la venta u oferta de esos bienes en plataformas de internet tiene vinculación con la posibilidad de comercialización fuera del territorio delimitado en la licencia ${ }^{52}$. Es decir, en relación con este aspecto, en principio, el derecho se habría agotado, pero también puede haber un motivo legítimo que haga que no sea así (vid. infra III).

29. Y, por otra parte, en la jurisprudencia se han planteado supuestos en los que no se permite al titular de una "licencia exclusiva" oponerse a una reutilización de un producto. En el caso concreto se trataba de bombonas de gas de material compuesto destinadas a ser reutilizadas -bombona protegida como marca tridimensional y en las que ese titular puso su nombre y su logotipo, registrados como marcas denominativa y figurativa-, en tal caso el titular no puede oponerse a que dichas bombonas, "después de ser adquiridas por consumidores que, seguidamente, consumieron el gas inicialmente contenido en éstas, sean cambiadas por un tercero, contra pago, por bombonas de material compuesto rellenadas con gas no procedente de ese titular, salvo que dicho titular pueda invocar un motivo legítimo en el sentido del artículo 7, apartado 2, de la Directiva 89/104"53.

\section{Carga de la prueba}

30. El TJUE se pronunciós ${ }^{54}$ a propósito de la carga de la prueba del agotamiento en relación con lo previsto en una norma nacional. En esta ocasión se concluyó que tal norma en materia de prueba según la cual el agotamiento del derecho de marca constituye un motivo de defensa para el tercero demandado por el titular de la marca, de modo que los requisitos de dicho agotamiento deben, en principio, ser probados por el tercero que lo invoca, es compatible con el Derecho comunitario. No obstante, se añadió que, en atención a la protección de la libre circulación de mercancías, puede requerirse que, si el tercero logra demostrar que existe un riesgo real de compartimentación del mercado, en tal caso, correspondería al titular de la marca acreditar que los productos fueron comercializados inicialmente por él o con su consentimiento, sobre todo si el titular comercializa sus productos a través de un sistema de distribución exclusiva. Acreditado ese extremo, entonces al tercero correspondería probar la existencia del consentimiento del titular para la ulterior comercialización de los productos en el EEE.

31. En esta materia, también se consideró ${ }^{55}$, como se anticipó antes al tratar del consentimiento, que éste debe expresarse positivamente y que los elementos que han de tenerse en cuenta para inferir

\footnotetext{
${ }^{50}$ Ap. 38, STJCE 22 junio 94, C-9/93, Ideal Standard, ECLI:EU:C:1994:261.

${ }^{51}$ STJUE 23 abril 2009, C-59/08, Copad, ECLI:EU:C:2009:260.

${ }^{52}$ Aunque relacionado con la concordancia de determinadas cláusulas con el Derecho Antitrust, conectado por tanto de forma indirecta con esta materia, v. A. Arroyo APARICIO, "Productos de lujo y distribución a través de plataformas de internet desde el Derecho Europeo de la Competencia (TJUE C-230/16, Asunto Coty)", Cuadernos de Derecho Transnacional, Vol. 11, n. 1, 2019, págs. 663-670.

${ }^{53}$ STJUE 14 julio 2011, C-46/10, Viking Gas, ECLI:EU:C:2011:485.

${ }^{54}$ STJCE 8 abril 2003, C-244/00, Van Doren, ECLI:EU:C:2003:204.

${ }^{55}$ STJCE 20 noviembre 2001, C-414/99 a C-416/99, Zino Davidoff, ECLI:EU:C:2001:617.
} 
la existencia de un consentimiento tácito deben revelar con certeza la renuncia del titular de la marca a oponer su derecho exclusivo ${ }^{56}$. En consecuencia, se consideró que corresponde al operador que invoca la existencia de consentimiento aportar la prueba correspondiente y no al titular de la marca acreditar la falta de consentimiento ${ }^{57}$.

\section{Importaciones paralelas, marcas de "origen común” y agotamiento}

32. El TJUE se ha pronunciado de forma destacada en cuatro ocasiones acerca de casos de titularidad en un primer momento en manos de una misma persona, pero fraccionada posteriormente, bien de forma voluntaria, bien por una medida de coacción pública. En esos casos se planteaba si el titular podía oponerse "a la importación en el territorio en el que su derecho está protegido de productos designados con la misma marca introducidos en el tráfico económico en un Estado miembro en el que la mencionada marca es titularidad de un tercero" 58 . Se trataría de las denominadas importaciones paralelas, materia conectada con el agotamiento y que afecta en gran medida a marcas nacionales independientes en manos de distintos titularse dentro del EEE. La jurisprudencia del TJUE al respecto resulta de gran interés en cuanto a la interpretación de las Directivas de marcas y la conexión del agotamiento con la delimitación de la "función esencial" de la marca, así como del agotamiento con los denominados "vínculos económicos".

33. En atención a la protección territorial, cabe considerar que en el caso en que los titulares de marcas nacionales sean distintos e independientes y se lleve a cabo una importación sin consentimiento del titular de la marca en el país de importación, no habría agotamiento europeo, aun cuando los productos marcados hubieran sido adquiridos lícitamente en el país desde el que se importa (superación de la teoría del "origen común"). Esto es, el agotamiento no se produce cuando las marcas pertenecen a titulares diferentes, aunque el origen fuera común y la distinción de las titularidades se hubiera producido mediante una transferencia voluntaria. Sí que habría agotamiento si: (i) el titular de la marca en el país de importación y el titular en el país de exportación son el mismo o (ii) tienen un vínculo económico ${ }^{59}$.

34. Ahora bien, conviene hacer dos puntualizaciones importantes en relación con el párrafo anterior. La primera puntualización consiste en que se recordará que las anteriores afirmaciones supusieron una rectificación de las primeras consideraciones del TJCE, pues, en un primer momento, se entendió que, cuando los dos derechos de marca tenían titulares independientes en el país de exportación y en el país de importación, pero ambos derechos provenían de un origen común, en tal supuesto se entendía que el agotamiento tenía lugar, de manera que el titular del derecho en el país de importación no podía ejercitar su derecho exclusivo para evitar que los productos se introdujesen en el mercado ${ }^{60}$. Pues bien, ese reconocimiento inicial del agotamiento en tales casos (asuntos Sirena y HAG I, años 1971 y 1974, respectivamente ${ }^{61}$ ) fue rectificado y dejado sin efecto a partir del año 1990 (HAG II), con su manifestación ampliada y clara en el año 1994 (IHT Internationale Heiztechnik/Ideal Standard).

35. La segunda puntualización consiste en la matización introducida en el asunto Schweppes $(2017)^{62}$, en el que se hace, además, una exposición cronológica de la jurisprudencia del TJUE sobre

\footnotetext{
${ }^{56}$ Zino Davidoff, cit., $\$ 53$.

${ }^{57}$ Zino Davidoff, cit., § 54.

${ }^{58}$ Conclusiones AG Paolo Mengozzi, 12 septiembre 2017, C291/16, Schweppes, ECLI:EU:C:2017:666, § 39.

${ }^{59}$ STJCE de 22 junio 1994, C9/93, IHT Internationale Heiztechnik y Danzinger, ECLI:EU:C:1994:261.

${ }^{60}$ A. BERCOVITZ, Introducción a las marcas y otros signos distintivos en el tráfico económico, 2002, p. 145.

${ }^{61}$ STJCE 18 febrero 1971, C-40-70, Sirena, ECLI:EU:C:1979:236; STJCE 3 julio 1974, C-192/73, Van Zuylen v. Hag, ECLI:EU:C:1974:72.

${ }^{62}$ STJUE 20 diciembre 2017, C291/16, Schweppes, ECLI:EU:C:2017:990. Sobre ella: M. Esteve SANZ, "La sentencia de 9 de abril de 2018 del Juzgado de lo Mercantil no 8 de Barcelona dictada en el caso "Schweppes", tras la Sentencia del Tribunal de Justicia de la Unión Europea, de 20 de diciembre de 2017" Aplicación del principio del agotamiento del derecho de marca a un particular supuesto de marcas de origen común o paralelas más de 20 años después de la "Sentencia Ideal Standard", Revista Comunicaciones $\mathrm{N}^{\circ}$ 83, (Enero-Abril 2018), pp. 91-114.
} 
esta materia. De hecho, tal y como se expresa en esta STJUE del año 2017, siendo esencial la función de designación de origen de la marca, ésta quedaría reducida si, faltando el consentimiento del titular, éste no pudiera oponerse a la importación de un producto idéntico o similar designado con una marca idéntica o que induzca a confusión, que ha sido fabricado y comercializado en otro Estado miembro por un tercero que no tiene ningún vínculo económico con ese titular ${ }^{63}$. Así, se considera que la función de garantía, consistente en que los productos designados con una marca tienen una procedencia única, no quedaría cumplida, cuando después de la cesión de una parte de las marcas paralelas nacionales a favor de un tercero, el titular "haya seguido promoviendo activa y deliberadamente la apariencia o la imagen de una marca global y única, creando o reforzando de este modo una confusión en el público pertinente en cuanto al origen empresarial de los productos designados con esta marca" ${ }^{\prime 64}$.

36. De ahí que en este caso se profundice, de manera destacada en las Conclusiones del AG, a propósito de qué ha de entenderse por "vínculo económico". Se entiende que hay un vínculo económico entre: un fabricante y su distribuidor; un licenciante y su licenciatario o bien en el supuesto de empresas que pertenecen al mismo grupo empresarial. La naturaleza de las relaciones entre ellos no es lo más relevante, sino que lo sería el resultado, entendido como la posibilidad de control por parte del titular, como criterio determinante del consentimiento del titular. De hecho, el AG considera que esta interpretación de "posibilidad de control" era incluso acorde con la opinión del TJCE en el asunto IHT Internationale Heiztechnik, así como que, para determinar si los derechos se agotan, el control unitario ha de permitir a las entidades que lo ejerzan determinar tanto los productos como su calidad.

37. El TJUE falla en esta ocasión, de manera tal que: el artículo 7 de la DM "debe interpretarse en el sentido de que impide que el titular de una marca nacional se oponga a la importación de productos idénticos designados con la misma marca y procedentes de otro Estado miembro, en el que esta marca, que pertenecía inicialmente al mismo titular, es actualmente propiedad de un tercero que ha adquirido los derechos relativos a la misma mediante cesión cuando, tras esta cesión,

- el titular, solo o coordinando su estrategia de marca con ese tercero, ha seguido promoviendo activa y deliberadamente la apariencia o la imagen de una marca global y única, creando o reforzando de este modo una confusión en el público pertinente en cuanto al origen empresarial de los productos designados con ésta,

o

- existen vínculos económicos entre el titular y dicho tercero, en el sentido de que coordinan sus políticas comerciales o se conciertan para ejercer un control conjunto sobre el uso de la marca, de modo que tienen la posibilidad de determinar directa o indirectamente los productos en los que figura dicha marca y de controlar su calidad."

\section{Modificación del estado de los productos y otros motivos legítimos}

\section{A) Ideas previas}

38. El agotamiento no se producirá en supuestos de mercancías con usurpación de marca, es decir, que lleven la marca sin el consentimiento del titular, cuya comercialización supone una violación del derecho, a la que el titular se puede oponer ${ }^{65}$.

39. Según el apartado $2^{\circ}$ del artículo 15 RMUE, cuando existan motivos legítimos que justifiquen que el titular se oponga a la ulterior comercialización, el derecho del titular no se agota. En

\footnotetext{
${ }^{63}$ Cfr. $§ 34$ STJUE, 20 diciembre 2017, C291/16, Schweppes, ECLI:EU:C:2017:990, que cita además: las sentencias de 17 octubre 1990, C 10/89, HAG GF, § 15 y 16, y de 22 junio 1994, IHT Internationale Heiztechniky Danzinger, C 9/93, §§ 33 a 37.

${ }^{64}$ Cfr. $\S 40$ STJUE 20 diciembre 2017, C291/16, Schweppes, ECLI:EU:C:2017:990.

${ }^{65}$ T. De las heras, "Marca comunitaria", cit., p. 414.
} 
especial, el artículo se refiere a cuando el estado de los productos se haya modificado o alterado tras su comercialización. Y, según el tenor literal -"en especial"-, resulta claro que esa cita es ejemplificativa y caben otros motivos legítimos. La búsqueda de cuáles puedan ser dependerá de las circunstancias específicas de cada caso, como se afirmó en relación con botellas de bebida (con re-etiquetado, supresión de números de identificación o la palabra "pure" y del nombre del importador en las etiquetas) ${ }^{66}$. Así mismo se ha afirmado que el titular de la marca ejercitará este derecho únicamente frente a otros operadores económicos ${ }^{67} \mathrm{y}$ en relación con mercancías que estén en el mercado ${ }^{68}$. Puesto que "cuando una persona física vende un producto de marca a través de un mercado electrónico sin que esta operación se enmarque en el contexto de una actividad mercantil, el titular de la marca no puede hacer valer el derecho exclusivo que le reconocen los artículos 5 de la Directiva 89/104 y 9 del Reglamento n ${ }^{\circ}$ 40/94"69. Ahora bien, en el caso de que las ventas realizadas en tal mercado electrónico superen, por razón de su volumen, su frecuencia u otras características, el ámbito de una actividad privada, entonces podría considerar que el vendedor actúa dentro del «tráfico económico» a efectos de los artículos mencionados.

\section{B) Re-envasado y re-etiquetado}

40. Son motivos legítimos: modificar o alterar, tras la comercialización el producto marcado, ya que el "titular de la marca tiene derecho a que el producto llegue a su destinatario final en las mismas condiciones en que él lo ha introducido en el mercado"70. Así, estos motivos legítimos se refieren a supuestos en los que se impide la función de marca con ocasión de una intervención posterior sin consentimiento del titular ${ }^{71}$.

41. Se trataría de supuestos de re-etiquetado y re-envasado, que surgen -principalmente, pero no solo- en relación con los medicamentos comercializados en diferentes países del EEE cuando esa modificación resulta necesaria para el acceso efectivo al mercado afectado o a una parte importante del mismo. El TJCE analizó que el titular podía prohibir la distribución en Alemania del producto comprado en una marca de un medicamento (Valium) en Reino Unido porque el re-envasado se había producido en circunstancias tales que no existía la garantía por parte del consumidor de que el producto no hubiera sido manipulado sin autorización del titular de la marca ${ }^{72}$, si bien había de atenerse a las circunstancias concretas; de ahí que, por ejemplo, el agotamiento sí se produjo sin embargo en el asunto "Vibramicina"73 donde había garantías de no manipulación del producto pese al re-envasado.

42. Es cierto que el sector de productos farmacéuticos se presta especialmente a este supuesto, aunque se ha indicado la posible extensión a otros productos en cuanto a los argumentos básicos ${ }^{74}$.

43. Como es sabido, sobre esta materia, el TJCE había fijado unas condiciones (conocidas como “condiciones BMS", provenientes de las iniciales del asunto en el que se fijaron ${ }^{75}$ ); condiciones que los importadores debían cumplir para evitar una infracción de marca, en los supuestos de importaciones paralelas, referidas al re-empaquetado o re-etiquetado de productos farmacéuticos. En el posterior asunto

\footnotetext{
${ }^{66}$ STJCE 11 noviembre 1997, C-349/95, F. Loendersloot Internationale Expeditie - Ballantines, ECLI:EU:C:1997:530, §§ 31,38 y ss.

${ }^{67}$ STJUE 12 julio 2011, C-324/09, L'Oréal-eBay, ECLI:EU:C:2011:474, § 54.

${ }^{68}$ STJUE 12 julio 2011, C-324/09, L'Oréal - eBay, ECLI:EU:C:2011:474, § 54, con cita además de: STJCE 16 noviembre 2004, C245/02, AnheuserBusch, ECLI:EU:C:2004:717, § 62 y de 18 junio 2009, C487/07, L'Oréal y otros, ECLI:EU:C:2009:378, §57.

${ }^{69}$ STJUE 12-VII-2011, C-324/09, L'Oréal-eBay, ap. 55.

${ }^{70}$ Entre las antiguas, STJ de 23-V-1978, C-102/77, as. Valium, Hoffmann-La Roche.

${ }^{71}$ P. Martín ARESTI, Comentarios, sub art. 36, cit., p. 595.

${ }^{72}$ Cfr. in extenso: Conclusiones AG F. G. Jacobs, 14 diciembre 1995, C-427/93, Bristol-Myers Squibb, ECLI:EU:C:1995:440.

${ }^{73}$ STJCE 3 diciembre 1981, C-1/81, Pfizer / Eurim, ECLI:EU:C:1981:291.

${ }^{74}$ STJCE 11 noviembre 1997, C-349/95, Frits Loendersloot c. George Ballantine \& Son Ltd. y otras, ECLI:EU:C:1997:530.

${ }^{75}$ STJCE 11 julio 1996, C-427/93, Bristol-Myers Squibb v. Paranova, ECLI:EU:C:1996:282.
} 
Boehringer Ingelheim ${ }^{76}$, se resolvió sobre el artículo 7.2 de la Directiva 89/104, en el sentido de que el titular de una marca podrá invocar su derecho de marca para impedir a un importador paralelo llevar a cabo un re-envasado de medicamentos, salvo que el ejercicio de dicho derecho contribuya a compartimentar artificialmente los mercados entre los Estados miembros. Este pronunciamiento también consideró que: "un re-envasado de medicamentos mediante sustitución del embalaje es objetivamente necesario en el sentido de la jurisprudencia del Tribunal de Justicia si, de lo contrario, se obstaculiza el acceso efectivo al mercado de que se trate o a una parte importante de éste debido a una fuerte resistencia de una proporción significativa de consumidores frente a los medicamentos re-etiquetados". También concluyó que el importador paralelo debe respetar en todo caso el requisito de advertencia previa al titular de la marca para tener el derecho a realizar el re-etiquetado.

44. Pues bien, en el asunto Junek Europ-Vertrieb GmbH v. Lohmann \& Rauscher International $G m b H \& C o K G^{77}$ se hace alusión a la interpretación que el TJUE venía realizando y se concretaba en considerar que "la oposición del titular de la marca a la comercialización de medicamentos re-envasados, de conformidad con el artículo 13, apartado 2, del Reglamento n. ${ }^{\circ}$ 207/2009, que constituye una excepción a la libre circulación de mercancías, no se puede admitir si el ejercicio por el titular de este derecho constituye una restricción encubierta del comercio entre los Estados miembros en el sentido del artículo 36 TFUE (sentencias de 11 de julio de 1996, Bristol-Myers Squibb y otros, C427/93, C429/93 y C436/93, EU:C:1996:282, y de 26 de abril de 2007, Boehringer Ingelheim y otros, C348/04, EU:C:2007:249). De ello se deduce que el titular de la marca puede prohibir la modificación que implica todo re-envasado de un medicamento que lleve su marca y que, por su propia naturaleza, cree el riesgo de un perjuicio al estado original del medicamento a menos que se cumplan cinco requisitos, a saber:

- que se acredite que la utilización del derecho de marca, por parte de su titular, para oponerse a la comercialización de los productos re-envasados con esta marca contribuiría a compartimentar artificialmente los mercados entre Estados miembros;

- que se demuestre que el re-envasado no puede afectar al estado original del producto contenido en el embalaje;

- que se indique claramente en el nuevo embalaje el autor del re-envasado del producto y el nombre del fabricante de este;

- que la presentación del producto re-envasado no sea tal que pueda perjudicar la reputación de la marca y la de su titular; así, el embalaje no debe ser defectuoso, de mala calidad o descuidado, $\mathrm{y}$

- que el importador advierta, antes de la comercialización del producto re-envasado, al titular de la marca y le proporcione, a petición de este, un ejemplar del producto re-envasado."

45. Ahora bien, en el supuesto Junek concreto, el tribunal alemán preguntaba si se aplicaban las "condiciones BMS" a las importaciones paralelas de dispositivos médicos del mismo modo que se habían aplicado a los productos farmacéuticos. El TJ considera que incluso teniendo en cuenta que los dispositivos médicos no son equiparables a los productos farmacéuticos, sometidos a procedimientos de autorización, se tenía en consideración que "son productos que tienen una relación directa con la salud. Dado que los consumidores conceden un especial valor y atención a la salud, nada hay que objetar a la apreciación del tribunal de apelación en el sentido de que los dispositivos médicos, al igual que los medicamentos, figuran entre los productos especialmente sensibles en que, debido a la elevada responsabilidad del fabricante, adquiere una especial relevancia la garantía de procedencia que otorga la marca indicada en el producto".

46. Por tanto, se confirma que las condiciones "BMS" se aplican también en el caso de dispositivos médicos, si se ha llevado a cabo un re-envasado. Pero también sugiere -y esta es la novedad- que hay un umbral de minimis aplicable al concepto de re-envasado que no incluye una pequeña etiqueta adicional

\footnotetext{
${ }^{76}$ STJCE 23 abril 2002, C-143/00, Boehringer Ingelheim KG, ECLI:EU:C:2002:246.

${ }^{77}$ STJUE de 17 mayo 2018, C-642/16, Junek, ECLI:EU:C:2018:322.
} 
discretamente colocada que no parece que pueda poner en peligro las funciones de marca). En resumen, en esta ocasión se considera que el antiguo artículo 13, apartado 2 del Reglamento 207/2009, que se correspondería con el hoy 15.2, ha de interpretarse en el sentido de que el titular de una marca no puede oponerse a una mayor comercialización, por parte de un importador paralelo, "de un dispositivo médico en su embalaje interior y exterior original cuando el importador ha colocado una etiqueta adicional, como la controvertida en el litigio principal, que por su contenido, función, tamaño, presentación y emplazamiento no supone un riesgo para la garantía de la procedencia del dispositivo médico que lleva la marca".

\section{C) Publicidad}

47. El titular de una marca no puede oponerse a que un operador económico, que habitualmente comercializa artículos del mismo tipo pero no necesariamente de la misma calidad que los productos protegidos, utilice dichos productos, conforme a los métodos usuales en su ramo de actividad, para anunciar al público la comercialización ulterior de los mismos, a menos que se demuestre que, habida cuenta de las circunstancias específicas de cada caso, el empleo de dichos productos a estos efectos menoscaba gravemente la reputación de los mismos ${ }^{78}$. Afirmado lo anterior por el TJUE, un motivo legítimo para oponer la marca a una comercialización ulterior o publicidad sería el supuesto en el que pudiera dañar seriamente la reputación de la marca ${ }^{79}$. Así se ha considerado cuando el anuncio, aunque no sugiera la existencia de un vínculo económico, sea tan impreciso sobre el origen de los productos de que se trata, "que un internauta normalmente informado y razonablemente atento no puede determinar, sobre la base del enlace promocional y del mensaje comercial que lo acompaña, si el anunciante es un tercero para el titular de la marca o si, por el contrario, está económicamente vinculado a éste" ${ }^{\text {" }}$, en tal caso se infiera que la función de marca resulta menoscabada.

\section{D) Otros motivos legítimos}

48. Anteriormente se mencionó el supuesto de reutilización de botellas de gas ${ }^{81}$. En este supuesto se consideró que el titular no podía oponerse al rellenado de las botellas (no se apreciaría motivo legítimo en este caso), si bien el TJUE apunta en el apartado 40 que, en relación con supuestos similares, debería estarse a "las prácticas en ese sector y, en particular, por lo que atañe a la cuestión de si los consumidores están habituados a que las bombonas de gas sean rellenadas por otros distribuidores". Así mismo, podrían considerarse como otros motivos legítimos el encontrar defectos en los productos marcados, que puedan implicar responsabilidad o daños ${ }^{82}$.

\section{Algunos aspectos en relación con el Brexit}

49. Desde la perspectiva del Reino Unido el agotamiento de los derechos de propiedad intelectual se fue introduciendo al implementar los textos europeos. Así, podía verse, la sección 12 de la Ley de marcas de 1994 (The Trade Marks Act 1994) que implementó el artículo 7 de la Directiva de marcas comerciales 89/104 / CE (ahora artículo 15 de la Directiva (UE) 2015/2436).

50. Y, como se recordaba al inicio, poco después de la entrada en vigor de la Directiva de marcas 89/104/CE, el TJCE aclaró si esa Directiva dejaba a los Estados miembros la posibilidad de establecer

\footnotetext{
${ }^{78}$ STJCE 4 noviembre1997, C-337/95, Parfums Christian Dior, ECLI:EU:C:1997:517, en el fallo.

${ }^{79}$ BeKEMA, cit., p. 457.

${ }^{80}$ STJUE 8 julio 2010, C558/08, Portakabin Ltd., ECLI:EU:C:2010:416, § 35.

${ }^{81}$ STJUE 14 julio 2011, C-46/10, Viking Gas, ECLI:EU:C:2011:485.

${ }^{82}$ BeKEMA, cit., p. 458.
} 
el agotamiento internacional ${ }^{83}$. Como es sabido, la respuesta fue clara, en tanto que no se permitía el agotamiento internacional, como forma de salvaguardar el funcionamiento del mercado interior. Es cierto que otra opción no parecía la adecuada si se permitía que algunos Estados miembros previeran el agotamiento comunitario mientras que otros lo hicieran respecto del agotamiento internacional. Y se recordará que esta posición permitía y permite la libre circulación dentro del espacio europeo.

51. Partiendo de esa situación, el Acuerdo del Brexit ${ }^{84}$ recoge un Título dedicado a la Propiedad intelectual, si bien fue seguido del Acuerdo de Comercio y Cooperación celebrado entre la UE y el Reino Unido que establece regímenes preferenciales en ámbitos como el comercio de bienes y servicios, el comercio digital, la propiedad intelectual, la contratación pública, entre otros. En este Acuerdo de Comercio y Cooperación, el Artículo IP.5 se limita a señalar, en cuanto al agotamiento, que el título del Acuerdo no afectará a la libertad de las Partes para determinar si se aplica el agotamiento de los derechos de propiedad intelectual, y en qué condiciones.

52. En este contexto, se replantearon antiguas cuestiones como el tipo de agotamiento que sería deseable establecer -nacional, internacional o regional-, se publicaron informes sobre la situación ${ }^{85}$ y el propio Gobierno del Reino Unido publicó normas específicas en la materia. Se trata de las normas sobre agotamiento de derechos: "The Intellectual Property (Exhaustion of Rights) (EU Exit) Regulations $2019^{\prime \prime 6}$. Estas normas recogen un agotamiento regional, en esencia y por ellas se modifica, entre otras, la Ley de Marcas de 1994 (The Trade Marks Act 1994) ${ }^{87}$. La pretensión general es la de mantener el status quo en la medida de lo posible.

53. Por otra parte, desde la perspectiva de las marcas europeas del RMUE, a partir del 1 de enero de 2021, ya no estarían protegidas en el Reino Unido ${ }^{88}$. Ahora bien, se previó que la Oficina del Reino Unido otorgaría automáticamente una marca comercial comparable a los titulares de marcas europeas totalmente registradas antes del 1 de enero de 2021, buscándose la equiparación con el mantenimiento de la fecha de presentación original de la marca europea, así como la fecha de prioridad original. Se ha previsto también en la Guía de la Oficina británica de propiedad intelectual la numeración de las marcas. Así mismo, se prevén aspectos como la renovación o la posibilidad de "opt-out", bajo condiciones, esto es, el titular de marcas de la UE que no esté interesado en ser titular de marcas comparables del Reino Unido puede optar por no acogerse, presentando una solicitud; se trataría de un supuesto de exclusión voluntaria que ha de cumplir determinadas condiciones, tanto para ser efectiva frente a terceros, como para ser una opción en sí (ya que no cabría en todos los supuestos).

54. Existen otras cuestiones importantes que han de ser consideradas, como sería el supuesto de las solicitudes de marcas de la UE que estuvieran presentadas ante la EUIPO y pendientes de resolución a fecha 31 de diciembre de 2020. En este caso, si el solicitante de la marca europeo desease conseguir protección marcaria también en el Reino Unido para el mismo signo, así como para los productos o servicios, que han sido solicitados a nivel de la UE, deberá el solicitante instar también una marca comercial británica equiparable contra el pago de las tasas británicas, antes del 30 de septiembre de 2021 (incluido).

\footnotetext{
${ }^{83}$ As. Silhouette v. Hartlauer, C-355/96.

${ }^{84}$ Acuerdo sobre la retirada del Reino Unido de Gran Bretaña e Irlanda del Norte de la Unión Europea y de la Comunidad Europea de la Energía Atómica (2019/C 384 I/01).

${ }^{85}$ Cfr. EY, Exhaustion of Intellectual Property Rights, estudio publicado en 2019, encomendado por la IPO (Intelectual Property Office, británica).

${ }^{86}$ STATUTORY INSTRUMENTS 2019. No. 265, EXITING THE EUROPEAN UNION, INTELLECTUAL PROPERTY, de 14 de febrero de 2019 y disponibles en: https://www.legislation.gov.uk/.

${ }^{87}$ Cfr. la Sección 12.

${ }^{88} \mathrm{Cfr}$. EU trade mark protection and comparable UK trade marks, Guidance for businesses and organisations holding EU trade marks at the end of the transition period.
} 
55. No cabe duda de que otros aspectos relevantes en materia de marcas pueden plantear algunos problemas. Así, surge evocar también, citándolos tan solo, aspectos como el uso genuino de la marca o la reputación del signo a partir del fin del año 2020. Igualmente, las licencias o las garantías reales inscritas en el registro antes del 1 de enero de 2021 se abordan en la Guía editada por la Oficina británica de Propiedad intelectual que, en conjunto, analiza, además de los arriba referenciados: todos los aspectos referidos a la denominada "marca comparable" en el Reino Unido; aspectos sobre una solicitud de MUE pendiente como marca del Reino Unido; las reivindicaciones de prelación y antigüedad junto con la retención automática de las fechas de prioridad y antigüedad existentes citadas; acciones de cancelación pendientes; el también ya citado uso y reputación; así como la certificación y marcas colectivas. 